2016-04-10

\title{
Exploring schools' use of natural spaces
}

\section{Gilchrist, M}

http://hdl.handle.net/10026.1/4823

10.1007/978-981-4585-99-6_18-1

Springer

All content in PEARL is protected by copyright law. Author manuscripts are made available in accordance with publisher policies. Please cite only the published version using the details provided on the item record or document. In the absence of an open licence (e.g. Creative Commons), permissions for further reuse of content should be sought from the publisher or author. 
This is the final authors' draft of the chapter; full reference below

Gilchrist, M., Passy, R., Waite, S. \& Cook, R. (2016) Exploring schools' use of natural spaces, in Freeman, C. \& Tranter, P. (eds) Risk, Protection, Provision and Policy, Vol. 12 of Skelton, T. (ed) Geographies of Children and Young People. Springer, Singapore, doi:10.1007/978-981-4585-99-6 18$\underline{1 .}$

\title{
Key words
}

\section{Outdoor learning, natural environment, schools, curriculum, play, Natural Connections Demonstration Project,}

\author{
Exploring schools' use of natural spaces \\ Martin Gilchrist, Rowena Passy, Sue Waite and Rachel Cook
}

\begin{abstract}
This chapter focuses on the changing ways in which schools are using natural spaces as part of their pupils' learning experience. We suggest that learning in natural spaces has undergone something of a renaissance in recent times, and explore the reasons that this might be so. We then examine ways in which schools and other practitioners are using outdoor spaces for play, for non-curricular and for curricular learning. The chapter draws on a range of countries for examples that show how a nation's cultural ideas about the outdoors can be incorporated into a country's outdoor learning, and how other ideas travel across boundaries to be interpreted in different practical ways. Within these sections, we consider different theoretical underpinnings that inform learning outside. Finally, the benefits of and challenges to outdoor learning are considered.
\end{abstract}

\section{Introduction}

There is a long-standing tradition of longing for times when life was more rural and therefore 'better', with the first example arguably being that of humanity's ejection from the Garden of Eden. But a yearning for a stronger relationship with the natural world became increasingly apparent from the mid-eighteenth century as the industrial revolution caused a rapid expansion of towns and cities; the intellectual and artistic Romantic movement, followed by the Pre-Raphaelites, for example, combined social criticism with a longing for a closer connection with nature - although the latter found themselves 'paradoxically poised between nostalgia for the past and excitement about the future' (Roe, n/d). And thinkers such as Durkheim, Marx and Simmel provided early theorisation of the relationship between nature and society (e.g. Gross, 2001; Järvikoski, 1996), with Marx in particular showing awareness 
of the conflict between 'short-term capitalist exploitation of natural resources and longer-term sustainable production' (Eagleton, 2011, p.229).

Abstract desire for the bucolic, however, was followed by action of a more practical nature. During the late nineteenth century, for instance, the establishment of National Parks in the US and Australia encouraged and protected both people's engagement with the natural world and the wildlife within it, and provided a model that is followed by a large number of countries today. This type of conservation work has subsequently been developed and augmented into a wide-ranging social and political environmental movement that includes international and local organisations, political parties, scientists and individual advocates. And over the last fifteen years or so, it has been possible to see a parallel process of increased awareness of and advocacy for the value of the natural world within the education sector, whereby children and young people's diminishing engagement with the natural world (e.g. Louv, 2008) has led to something of a renaissance in the use of outdoor spaces for teaching and learning among different nations across the globe.

In this chapter we discuss why this may be so, the ways in which teachers and other practitioners who educate pupils up to the age of sixteen are using the outdoor environment, and the different effects this has. We present research on outdoor learning from different nations to illustrate different debates, and describe briefly our own contribution to this body of work through the Natural Connections Demonstration Project. Finally, we bring the chapter to a close with a range of recommendations for the future. Our discussion includes all aspects of learning outside the classroom in the natural environment such as adventure education, curricular learning outdoors in a variety of settings such as school grounds or national parks, and more informal types of learning that might take place in, for example, other outdoor activities and / or residential settings.

\section{Patterns of change - why a renaissance of learning in the natural environment?}

Learning in the natural environment for children follows a tradition dating back from educationalists such as Fröbel and Pestalozzi in the nineteenth and early twentieth century, and was firmly established within Scandinavian nations through the idea of 'friluftsliv' (or open-air living), and in Germany through the Kindergarten movement. In the UK education in the outdoors was established along more class-based ideas, and in the independent or feepaying school sector there was an emphasis on character-building for future leaders. Activities in these schools included sailing, walking, expeditions and camping and these, together with sports such as rugby and cricket, were believed to encourage qualities of courage, loyalty, endurance, self-denial and public spirit in schools that aimed to produce disciplined, socially responsible and self-reliant young men who were future leaders of the nation and its colonies (Cook, 1999, p.58). For the working classes in the state-maintained sector, however, learning outdoors was seen as a kind of moral education, particularly for those who lived in rural areas and might otherwise be drawn to the 'lower' attractions of town 
life. The aims of this type of education were to awaken pupils' sense of wonder, develop their sympathy for nature and provide a practical context for their scientific and botanical studies (Jenkins and Swinnerton, 1998, p.63-4).

Nonetheless changing global economic fortunes during the late twentieth century led to a decline in the use of the outdoors for children's learning. Partly in response to the stagflation of the 1970s, a neoliberal reform agenda was launched in the UK and US during the Thatcher-Reagan era of the 1980s and subsequently disseminated to other parts of the world (Steiner-Khamsi, 2012). This agenda rests on assumptions of the efficiency of the free market in allocating resources, of the self-interested individual who will make rational decisions in optimising his or her welfare (however defined) and a belief in the market's capacity to self-regulate (Passy, 2013). When brought to the educational arena, neoliberalism encourages change to the structure of national systems in ways that include (degrees of) marketisation and privatisation, competition and new forms of accountability to national and local government. It can also include central control over teaching content through national or state curricula, detailed specification of teachers' work, close monitoring of teacher performance, and 'centralized high-stakes testing regimes' that 'continually evaluate the output of teaching by rendering it visible, calculable and comparable' (Clarke, 2013, p.230).

By and large, in circumstances linked to other developments that include changes in teacher training and reductions in funding, teachers' response, particularly in the UK, has been to reduce time outside in order to focus more insistently on those subjects that are measured in standardised tests (e.g. Taylor et al, 2010; Waite, 2010). However, research suggests that standards-based education systems that are focused on restricted cognitive outcomes entail other risks, including encouraging schools and teachers to narrow the curriculum which, in turn, reduces pupils' creative and enjoyable activities, restricts their thinking skills (Bangs, et al, 2011; Berliner, 2011; see also Robinson, 2010) and may fail to encourage them to become 'wise' in the sense of exercising good judgement based on moral understandings (Allison et al, 2012). In other words, while these systems may stimulate higher national test scores, they may at the same time be failing to support the development of flexible, creative and resilient young people by limiting their enjoyment of and disengaging them from wider processes and experiences of learning. It is in this context that teachers have started although there has always been a core of those who have believed in the value of learning outdoors - to re-discover how children and young people benefit from learning in a wide variety of contexts outdoors. We return to this subject later.

Meanwhile there are other developments that have contributed to a re-awakening of interest in learning outdoors, stemming from the diminishing amount of time that children generally spend outdoors. Louv's phrase 'nature-deficit disorder' (Louv, 2008), coined to summarise what he saw as a major shift in contemporary childhood experience, provides a succinct description of the situation that has become an entry-point for a wide range of discussions around the relationship between children and the natural world, despite the absence of 
medical evidence to support such a 'condition'. There is a now growing body of evidence that demonstrates how children and young people are leading an increasingly indoor-based, sedentary life. In a review of research from the US, UK, Canada, Australia, Germany, the Scandinavian countries and Japan, Charles and Louv (2009) argue that, with approximately 50 per cent of the world's population now living in urban areas - and a population share that is forecast by the United Nations Population Division to rise to 65 per cent in 2030 - there are 'strong indicators' that many children have no direct experience with the natural world in their everyday lives. These findings are corroborated by Natural England's (2013) MENE research, a longitudinal study of the English population's engagement with the natural environment.

This 'nature-deficit', they suggest, is for a number of reasons: research shows that urbanisation restricts population access to green spaces, that children have less free and unstructured outdoor playtime than previous generations and that they are more restricted in their playtime areas - they are allowed less range for exploration, including walking or cycling to school. A significant contributor to these restrictions is an increasing fear of strangers, traffic and of 'nature itself' (Charles and Louv, 2009), the latter partly brought about by the lack of familiarity and knowledge that comes with close contact with the natural world. In another research review, Moss (2012) adds the attraction of screen-based home entertainment as a barrier to children and young people being outside, and cites a UK Children's Society poll in which almost half of adults questioned believed that the youngest children should be allowed out unsupervised was 14 - leading to what has been described as 'well-meaning, protective house arrest' (Louv 2008, cit. Moss, 2012).

There is also an expanding research area that demonstrates a number of problems or issues related to a sedentary, indoor-based lifestyle. The first relates to children's physical health. Probably the most important contemporary issue is obesity, defined as 'abnormal or excessive fat accumulation that may impair health' (WHO, 2015). Worldwide obesity has more than doubled since 1980, with 42 million children under the age of five overweight or obese in 2013. Once considered a high-income country problem, obesity is now seen in lowand middle-income countries, particularly in urban areas, and the WHO argues that this is partially caused by 'an increase in physical inactivity due to the increasingly sedentary nature of many forms of work, changing modes of transportation, and increasing urbanization'. Childhood obesity is linked with a higher chance of conditions that include adult obesity, breathing difficulties, hypertension, increased risk of cardio-vascular disease and diabetes (WHO, 2015). In addition, there is a rising number of children and young people who are suffering from conditions such as vitamin D deficiency and/or shortsightedness (Charles and Louv, 2009; Moss, 2012), and there is evidence of a major decline in children's cardiorespiratory fitness and strength levels (Moss, 2012).

The other significant aspect to children's health is their wellbeing. Again defined by the WHO (2014), mental wellbeing (or health) is 'a state of well-being in which an individual realizes his or her own abilities, can cope with the normal stresses of life, can work productively and 
is able to make a contribution to his or her community'; poor wellbeing is associated with, among other things, stressful work conditions, an unhealthy lifestyle and social exclusion. There is now a wider understanding that children and young people can suffer from conditions such as depression and, in the UK, research shows that there has been an increase of 69 per cent in the number of young people admitted to hospital because of selfharming; around 80,000 children and young people suffer from severe depression and around 1 in 10 children and young people aged 5 -16 suffer from a diagnosable mental health disorder (YoungMinds, 2015). In the US, it is estimated that between 13 and 20 per cent of children experience a mental disorder in a given year (Centres for Disease Control and Prevention, 2013). In response to these health issues, a growing body of research shows the physical and wellbeing benefits that can be derived from time in the natural environment (see, for instance, Charles, 2012 for an extensive literature review on this subject).

Finally, it is possible that children and young people's detachment from the natural world contributes to their ignorance of and reduced sense of responsibility for the environment. In a research review, Loge (2009) cites a longitudinal study from the US in which trends in environmental attitudes, beliefs and behaviours of around 10,000 nationally-representative adolescents between 1976 - 2005 were analysed. The researchers found 'steep declines' in adolescents' willingness to participate in conservation activities such as reducing electricity or heat consumption, or driving less, and that they were increasingly likely to support government responsibility to protect the environment rather than take personal action. The authors also reported negative associations between materialism and personal environmental responsibility and conservation. Loge comments that, while the study may be limited due to the limited range of conservation behaviours that were investigated, it is unique in that it examines adolescents' attitudes to environmental issues among a nationally representative sample of young people over time. Other research in this area highlights young people's distance from the natural world by focusing on their (in)ability to identify common wildlife species in their area; a study in England found that one-third of children interviewed could not identify a magpie and half could not tell the difference between a bee and a wasp (see Moss, 2012). A similar study in Germany, that found for example that 30 per cent of a sample of 3,000 young people aged 12-15 had never touched a live beetle, and that one in five had never walked across a stubble field, encouraged Becker (2015) to reflect on the consequences of this; he argues that direct physical and sensory experiences are a necessary part of young people's developmental and educational processes and that they should not be limited to the 'cognitive visual' encounters with the world that are offered by modern screen technology offers. He quotes Steiger to illustrate his point:

The most talented teacher in the classroom is a miserable bungler compared to the mastership of nature. When we had found 23 fire salamanders in the valley of Zschand before the sun had risen on the dew-wet ground and we touched the slimy cold-blooded animals, marvelled at their serenity and gained detailed insights into the way they 
live, I thought of how the fire salamander would be discussed in the stayat-home school, where nature is presented in the form of a miserable terrarium, a corpse preserved in spirit or a poor picture-a long way away from experiencing nature. (Steiger, n.d., p. 17, cit Becker, 2015, p.81).

To summarise, concern over the educational process in schools, over children and young people's health and wellbeing, and over the future of the natural environment have contributed to a re-awakened interest among teachers and other practitioners in learning outside the classroom in natural environments. In the next section, we explore research evidence relating to teachers' use of natural spaces.

\section{Schools and using natural spaces}

Underpinning the arenas and conditions for children's play and education are a number of factors in each nation; its population size, geographical area and terrain, policy priorities and financial situation (in terms of funding levels for play and education facilities and for staff training and development) all play a structural part in the way outdoor learning and play may be conceived and delivered. These factors can then be linked with educationalists' cultural and pedagogical beliefs and values. It follows that both across and within nations, learning outdoors has a wide range of aims, and there is a correspondingly wide range of activities and environments that teachers can use to take their pupils outside. Becker (2015) argues that both 'the tamed garden and untamed nature' have a place for learning - the garden, or cultivated space, can be used broadly for beneficial application of knowledge while wilder parts of nature can allow the creation of new types of knowledge; pupils are more likely in these environments to confront new situations and come to new understandings, whether about self, others or the wider world (Waite, 2013). Thus, while Forest School, day trips, school grounds, residential stays in outdoor education centres and adventure education (that may include trips involving mountains, rivers and/or forests) all offer different types of learning and experience, there is widespread agreement that pupils can derive a range of benefits that include a healthier, more self- and environmentally-aware life for children and young people. We discuss these benefits in more detail in the next section. In this section we describe a number of different types of outdoor learning, drawing on examples of international research to illustrate the different themes of outdoor play, approaches to noncurricular learning outside, and curricular learning.

\subsection{Outdoor play}

One aspect of outdoor learning emphasised in the literature is that of outdoor play. Play, a complex concept that can be defined as concerning children's 'own' or self-directed activity, in which the activity itself is more important than the outcome (Waite et al, 2013), is widely regarded as essential to children's development, particularly for young children. Outdoor play is seen as different to (generally) more structured indoor play, partly through the elements of risk and unpredictability afforded by playing outside in natural environments; the 
'scary-funny' feeling, where children shift between negative and positive emotions during the course of play outside, is believed to support them in learning to manage uncertainty, deal with new challenges and through this, to strengthen their physical and emotional skills (Niehues et al, 2013). Areas for outdoor play within an educational setting can include nursery, kindergarten or school grounds, plus local wild spaces such as forests; Luchs and Fikus (2013) argue that a relatively new form of 'natural playgrounds' has developed in Germany, which offer a playscape that is nature-oriented and may contain uncultivated natural areas, lots of trees and vegetation, dirt, rock structures, natural water areas and natural fences. Equipment in these playgrounds tends to be made of natural materials such as wood and rope rather than the plastic and metal associated with traditional playgrounds.

Approaches to outdoor play can differ widely between countries. In Norway and other Scandinavian countries, for example, there is a strong cultural attachment to nature, and there are extensive outdoor play areas for kindergarten-aged children that may include a sand pit, a slope or a climbing area. In addition, play and activity in the natural forest landscape 'are part of the everyday kindergarten experience' in Norway, and children play outside in these different environments for several hours a day, in summer and winter, and in all weathers - holding to the Scandinavian maxim that there is no such thing as bad weather, just inappropriate clothing (Aasen et al, 2009). In England, however, there is a different, more cautious, approach: policy states that childcare providers for young children up to the age of five 'must provide access to an outdoor play area or, if that is not possible, ensure that outdoor activities are planned and taken on a daily basis (unless circumstances make this inappropriate, for example unsafe weather conditions)' (DfE, 2014, p.28). Slovenia, a country that is densely-forested and therefore would seem to offer ideal conditions for time in the natural environment, presents something halfway between these two perspectives; outdoor play for preschool children is given no special statutory significance yet going outside is 'routine', with a relatively small amount of that time spent in natural environments (Kos and Jerman, 2013).

Linked to this is the concept of risk and appropriate levels of risk to which young children should be exposed. Comparative research is starting to show how differences within education systems can affect approaches to outdoor play and in particular the role that risk might have during such play. In a study focusing on Norway and Australia, for instance, Sandseter et al (2012) highlight the role that theoretical underpinning to training may have on practitioners' approach to play. Their findings show that, despite similar levels of training and similar beliefs about the role of play in children's learning, their sample of Norwegian teachers emphasised the opportunities for risky play in the outdoor environment while the Australian early years practitioners were more reluctant to allow potentially risky activities such as climbing trees; their principal focus was on promoting children's skills development or responding to children's interests. These practitioners argued that restrictive regulations were the main reason for limiting risky play, but the authors look beyond the immediate context; they comment that, although the reasons for the differences between the two samples are necessarily complex, the differing theories that underpin pedagogical 
approaches in the two nations' practitioner training could be an important factor in aligning their approach to the element of risk acceptable in outdoor play.

Differing theories and culture contribute to the approach to, and understanding of, how the outdoors is used in more formal education settings. In the next sections we explore these in relation to non-curricular and curricular learning, drawing on examples from different nations to show how ideas can cross boundaries and influence outdoor learning practice across different parts of the world.

\subsection{Approaches to non-curricular learning outside}

While structural, cultural and personal values and beliefs can result in different patterns of playing and learning outside both within and between countries, there is also evidence of cross-fertilisation between nations. The Scandinavian, and in particular Danish, approach seen in Forest Schools, for instance, has led to an increasing number of practitioners using the approach in England for young children (Elliot, 2013). Forest School activities take place in local wooded areas and, although different models exist, they are underpinned by a number of principles that include:

- organisation and delivery by a qualified practitioner

- inclusive practice: Forest School is for everybody

- offering children the opportunities to take risks, make choices and initiate learning

- frequent and regular visits to local woodland throughout the year

- attention to understanding and caring for the natural environment

(Passy and Waite, 2011).

Participating pre-schools and schools usually send classes or specific children to an organised Forest School for a morning or an afternoon session, where they become involved in a range of activities that include using tools to create art work, listening and responding to stories, learning about plants and habitats, tree climbing and different types of teamwork (O'Brien, 2009); the emphasis is on non-curricular learning in an environment that immediately offers more scope for freedom and creativity than the classroom. Although forest school is intended to be appropriate for all children, schools may also use it as a targeted intervention for those from socially deprived backgrounds or with particular social or behavioural needs who are felt to benefit most from what Forest Schools can offer.

Forest School is one example of learning outside that is not focused on a curricular subject but on the wider personal development that is seen to contribute to social and emotional wellbeing. Another example of this is what is generally termed outdoor or adventure education, which again has elements of cross-fertilisation of ideas and techniques across the world. Ho (2014), for instance, draws attention to the way in which fitness for war and service in the British empire and allied nations during World War I underpinned the use of the outdoors for educational purposes for boys; she argues that the influence of a neoHahnian approach, which emphasises initiative and self-discipline as part of a reaction 
against the earlier militaristic obedience to duty, can still be seen in outdoor education in the US, the UK, parts of Europe, New Zealand and Australia. She suggests that, while the emphasis in the other nations may have shifted to include other educational dimensions, outdoor education practices in Singapore 'continue to be entrenched in a neo-Hahnian outlook' and that developing young people's resilience is the main aim of outdoor learning policy. To that end, schools have to ensure that all students have at least one camping experience in their school life, and Ministry-funded adventure centres have been set up to help meet the demand. There is also an emerging trend for schools to take students on overseas trips to learn about other cultures, generally combining lessons with outdoor pursuits and community service in areas such as the jungles of Thailand, the mountains of New Zealand and the deep waters off Malaysia. Ho argues, however, that outdoor education in Singapore should have wider aims, with a greater emphasis on building social skills, ecological literacy and an emotional bond with the nation (Ho, 2014).

As Ho suggests, adventure education is practised in a wide number of countries, based originally on the idea that the experience will toughen participants and build their 'character' for leadership. However, as Brookes (2003) argues in a critique of neo-Hahnian outdoor education theory, every situation experienced by participants in outdoor education has a unique set of social, cultural and geographical elements that influence behaviour and, while the experience may shape behaviour in that particular context, it does not necessarily influence that in other situations. Similarly, uncritical acceptance of the idea that the outdoors is good for all students and that it influences their learning in similar ways across a number of dimensions is unhelpful (Zink and Burrows, 2008). This type of critical scholarship, that draws attention to assumptions, inconsistences and unsupported generalisations in outdoor learning, has led to a burgeoning literature on the aims, theoretical underpinning and methods of research into adventure education. For example Rea (2011) argues that residential outdoor education (where groups of children and young people stay in a centre away from home and participate in different outdoor physical activities), is now acknowledged to have a number of aims that may include new perspectives on risk-taking, valuing nature, sustainability, ecology, trust and reliance on peers, and managing homesickness; Rickinson et al (2004) suggest that adventure education programmes can have therapeutic, educational and recreational aims in varying proportions - each with specific goals within those aims. A range of different theoretical approaches that support the analysis of outdoor learning experiences can be found in Pike and Beames (2013), who draw on theorists as diverse as Elias, Foucault and Durkheim to explore the relationship between sport, culture and modern society.

Ho's suggestion that outdoor education can stimulate an emotional bond, whether with the nation, a particular part of the country or with nature itself, can be seen more explicitly in the concept of place-based education, a movement that Greenwood (2013) argues has 'gone global'. Beames and Ross (2010), for instance, advocate local educational programmes that contrast with 'narrow' adrenaline-fuelled adventures by providing more sustainable, local, broad adventures that can involve longer timescales. They argue that while a kayaking 
course may be fun and adventurous, it could happen anywhere in the world where there is a suitable watercourse, with the result that the place itself has little relevance for the students. They suggest that, although place-based education has a number of aims and purposes, its essence is to facilitate students' awareness of the geo-physical and socio-cultural story of the land around them; underpinning this idea is the assumption that the understanding reached will help students to develop a bond with the location. An example of this is provided by Stewart (2008), who uses place-based education as a means of reflecting on the relationships between personal experiences and the different cultural-ecological processes that shape the place in which we live and work. Highlighting Australia's history of poor relations between Aboriginal and non-Aboriginal leaders, he argues that it is essential for outdoor educators to consider carefully the ways in which they introduce students to the stories about historical ownership of the land, and how this has changed over time:

As an educator the choice of story, for me, is partly shaped by the landscape, what might be readable in the landscape, and what or who is silenced by omission (Stewart, 2008, p.87).

Drawing on his own practice, he shows how a canoe journey down the River Murray was 'full of cultural stories' that show how Aboriginal people have used the river and its environs; middens, scar trees, boundary marker trees, stone tools and burial sites all offer avenues for exploration and discussion on the ways in which different people have shaped the landscape over the years, and this can lead on to discussions about the relationship between settlers and the indigenous population. Equally, Stewart argues that it is easy not to pay attention to these sites - to employ a kind of 'practical forgetfulness' that ignores uncomfortable colonial history that, in turn, brings a real risk of repeating the past:

Without attending to history of places, we run the very real risk of repeating the past: dispossessing the inhabitants (figuratively) and denying their agency in creating the attributes of the place that are likely to have drawn us there in the first instance. There is no single history of a place: different stories reveal different values, attitudes, behaviour and impacts (Stewart, 2008, pp.93-4).

This section provides an introduction to different types of (generally) non-curricular learning, and shown how it can be used for a variety of educational experiences. We now move on to discuss curricular learning, both within and outside the school grounds, drawing specifically on the example of the Natural Connections Demonstration Project in the UK to illustrate how teachers can use their outside space during school time.

\subsection{Curricular learning}

One possible link between adventure education and more direct curricular learning is the notion of udeskole. Described as the 'newest development of education' in Denmark and Scandinavia (Bentsen et al, 2009), udeskole refers both to a method of teaching and a 
theoretical understanding that education takes place in a social, economic, political and geographical context. Originally a grassroots movement in Denmark that was initiated by enthusiastic teachers, Bentsen and colleagues regard udeskole as a form of counterculture to existing (largely indoor-based) educational practices, and summarise it as follows:

... udeskole has its target group of school children aged $7-16$, and is characterised by the fact that compulsory educational activities take place outside the walls/buildings of the school and are done on a regular basis (i.e. a day every or every other week) and can take place in nature, local communities, factories, farms etc.

(Bentsen et al, 2009).

Bentsen and Jensen (2012) argue that the purpose of this outdoor learning is to work with an academic matter or concept in its real, concrete form in order to facilitate learning and understanding. They argue that, in Denmark, an increasing number of teachers have started to introduce weekly or bi-weekly curriculum-based outdoor learning in which students may calculate the volume of trees for mathematics, write creatively in or about natural places or contextualise historical studies by visiting significant old buildings or places. Often the work, however, is cross-curricular. Their research shows that at least 14 per cent of all Danish schools have one teacher practising udeskole with some classes, with similar trends reported from Norway and Sweden. As it is a relatively new movement, it is now a rich area for research into pedagogical theory and practice (Bentsen and Jensen, 2012).

While udeskole is practised outside school grounds, there have been other developments within school grounds that encourage teaching and learning outside. One notable change is an increased interest in school gardens, particularly in the UK and the US (Passy, 2014); Blair (2009) argues that developing school gardens has become something of a national movement in the US as different states have become involved in programmes that promote school gardening (for instance The Edible Schoolyard Project http://edibleschoolyard.org/) while, in the UK, the Royal Horticultural Society currently has over 19,000 schools (from around 24,000) as members of its Campaign for School Gardening (http://apps.rhs.org.uk/schoolgardening/default.aspa). This popularity is partly because school gardens lend themselves to outdoor teaching and learning; they are generally on-site, their cost is relatively small, and issues related to health and safety can generally be managed without difficulty (Passy, 2014). With imagination, gardens can be made in schools with little or no green space; we have seen plants grown in receptacles that range from wellington boots and buckets to old tractor tyres and greenhouses made from soda bottles, offering both pupils and staff a chance to plant, tend and harvest both edible and non-edible produce. Other schools with plenty of space may have such luxuries as an orchard or a large enough growing area to provide produce for the school kitchen; whatever their size, school gardens can provide:

- an arena for different types of learning that complement and enrich the curriculum 
- a discrete area that facilitates pastoral care

- a focus that encourages parents and the local community to engage with and contribute to the school

- a source of pride, pleasure and enjoyment for the school community

(Passy et al, 2010).

To these may be added the opportunity for physical exercise; gardening can be hard work, and involving children and young people in the construction and maintenance of gardens offers school-time access to health-promoting outside activity.

As an area for direct curriculum learning, however, school gardens provide opportunities for experiential learning in different areas of the curriculum such as mathematics, science, environmental studies, nutrition, literacy and social science; according to Kellert, the garden provides 'a rich diet for cognitive development' by 'developing and reinforcing the child's capacities for empirical observation, analytical examination and evidentiary demonstration' (cit Blair, 2009, p.19). Learning activities are often cross-curricular. One school programme in South Carolina, for instance, encouraged pupils to stock gardens with plants grown from seed, keep census counts of the different types of butterflies and caterpillars, and collaborate with students in Mexican schools; other programmes focused on how a plant goes from seed to plate, introducing students to local sustainable food systems as they ate their own produce, composted food waste and connected with other growers and gardeners (Blair, 2009).

Tranter and Malone (2004) widen their area of research focus beyond the cultivated area to include the whole school grounds. They argue that school grounds can be an important place for environmental learning; school grounds with natural features such as woods, grassy areas, shrubs and ponds encourage children to play and learn more creatively, thereby stimulating informal learning that complements their curricular learning. Their research in primary schools in Australia shows that playing with loose materials such as branches, pine cones and stumps, building structures such as a series of jumps, and digging channels provide opportunities for children to engage in a practical way with the natural world and, through this, absorb curricular information on the environment in a different and complementary manner. They call for educators to have greater regard for planning school grounds in such a way that encourages environmental learning. And we expand on this theme of learning within school grounds in the following section, drawing on research from the Natural Connections Demonstration Project to explore other ways in which they may be used.

\subsection{The Natural Connections Demonstration Project: curricular learning in school grounds}

Funded by the Department for the Environment, Food and Rural Affairs, Natural England and English Heritage, and delivered by Plymouth University, the Natural Connections Demonstration Project is a direct response to the UK Government's White Paper The 
Natural Choice (HM Government, 2011) which pledges action to 'remove barriers to learning outdoors and increase schools' abilities to teach outdoors when they wish to do so' (p. 4). The project model is one of cascaded responsibility, with 150 schools across South West England developing their own ways of working outside in response to the benefits that they see for their own pupils from learning in natural places. One strict criterion for the project is that schools must not use motorised transport for these activities, so teachers are directed towards to using their school grounds and local natural spaces for outdoor learning.

In the project evaluation, teachers report that they use outdoor spaces to impart concepts, generate inspiration and increase students' enjoyment of and engagement in their curricular learning. Teacher and pupil project interviews suggest that the accessibility to, mixture of and transition between spaces appear to be important in making spaces useful for schools; often one space will be used for investigation and/or inspiration and another for reflecting on or summarising work. Playgrounds and tarmac spaces, although not natural, are important in being able to access and use wilder areas which may not have suitable 'teaching' spaces; they may also be used as a stepping stone from the classroom in generating both teacher and pupil confidence in working outside on a number of subjects. Chalk writing on playgrounds, for example, is used by some schools to develop creative writing, as teachers have found that pupils are more willing to be experimental because the work is less permanent than in their exercise books. Similarly, the addition of permanent playground markings, often for mathematics, has been seen in a number of project schools; examples include new ladders, clocks and blank grids. In one primary school children found that standing on a 100-numbered square meant they reached a better understanding of the relationships between numbers and scales than they would have through using more abstract methods indoors. Reaching a better understanding can then have a positive effect on the child's attitude to learning; the school reported that increasing the amount this type of practical learning has meant '....children who have been disengaged in particular subjects having another perspective and beginning to really embrace their learning.' (primary school teacher).

Project evaluation is also showing that many participating schools have increased their investment in the development, management and maintenance of their school grounds in ways that can encourage teachers to use them more often, more imaginatively. Primary schools in particular are developing and enhancing their grounds on an annual basis, not least because this provides real-life, experiential learning for each new cohort of pupils. For example Year 6 pupils (aged 10-11) in their final year of primary school often identify less used areas of the grounds and generate ideas about how to use them and implement these as part of becoming more independent and preparing for transition to secondary school. We have seen areas of seating installed in unused corners of school grounds or fire-pits for more adventurous extra-curricular activities. Other examples include designing and building chicken coops or building greenhouses in response to curriculum needs identified during lessons. In one secondary school we have seen pupils form a 'School Spaces Committee' to contribute to the development and management of the school grounds. 
At the same time developing the school grounds can sometimes facilitate the engagement and support of the wider school community. One primary school, for example, has a growing/farm area that is managed by a 'School Farm Community Committee', with members drawn both from within and without the immediate school community. This arrangement is an innovative measure that provides a local solution to different areas of need; the school's need for expertise and practical support with the work involved in garden development and maintenance has been met by local gardening enthusiasts, who are able to enjoy the use of the school grounds for their allotments.

This school has also used the development of the farm area to provide extended learning opportunities. These include researching options of ways in which the farm may be developed together with suppliers of products such as seeds and compost; finalising farm development plans and presenting these plans to the school governors; writing persuasively to suppliers for favourable deals on their products, and negotiating with potential businesses for support with development work. Teachers reported that seeing the development of their ideas through to implementation was rewarding and motivating for the children, and that the quality of pupils' work improved through engaging with these real-life experiences. As one teacher commented:

'...[the pupils] get a real purpose and therefore you get a higher quality literacy and numeracy out of the work that you are doing.' (primary school teacher).

Such real life experiences are also important to secondary schools in engaging students and enabling them to make connections to the world of work. One secondary school provides opportunities within its citizenship curriculum; students are encouraged to identify groups of local people in need, decide on a course of action to support them and then implement the plan over several months' regular work. One group decided to grow vegetables on the school allotment, and students have been mentored and supported in this task by local people with gardening expertise. The vegetables are donated to the local food bank who then distribute them to local families in need, and any produce over and above what is required by the food bank is sold at the local market; this provides opportunities for students to engage in enterprise activities, with any profit invested back into the allotment. As one teacher reported, this kind of opportunity anchors learning '...in real life and allows some children to see that there is a greater purpose to what they are doing than what they have been able to see before' (secondary school teacher).

As these sections suggest, there is a wide body of research into the area on the aims, types of experience and underpinning theoretical approaches to using natural spaces as part of children and young people's learning. In a short chapter such as this, we have not attempted a comprehensive summary of the available evidence, but sought instead to highlight a number of different approaches from a variety of different nations to give a flavour of what is 
possible and how learning outside in natural spaces can become an integral part of children and young people's school experience. We have begun to touch on the benefits that teachers see for pupils in these settings, and now assess these benefits together with the challenges to accessing them in the next section.

\section{Benefits of and challenges to learning outside}

In an early review of research into learning outside, Rickinson et al (2004) divide learning outside into the three categories of fieldwork and visits; outdoor adventure activities; and school grounds and community projects. They suggest that there are four broad areas of benefit for children and young people who participate in these different types of outdoor learning activity:

- cognitive - concerning knowledge, understanding and other academic outcomes

- affective - encompassing attitudes values, beliefs and self-perceptions

- interpersonal / social - including communication skills, leadership and teamwork

- physical / behavioural - relating to fitness, physical skills, personal behaviours and social actions

(Rickinson et al, 2004, p.16).

Taking each of the three categories of outdoor learning in turn, their analysis of research shows that fieldwork can have a positive impact on long-term memory, can lead to individual growth and improvements in social skills, and reinforces the link between the affective and the cognitive, which provides a bridge to higher order learning. Adventure learning can impact positively on young people's confidence, self-esteem, communication skills and ability to work in teams, although there is less evidence for cognitive and physical / behavioural outcomes. School grounds and community projects offer the greatest capacity to link to curriculum areas, and the authors report positive gains in science process skills and improved understanding of design and technology-related issues. They conclude that

Substantial evidence exists to indicate that fieldwork, properly conceived, adequately planned, well taught and effectively followed up, offers learners opportunities to develop their knowledge and skills in ways that add value to their everyday experiences in the classroom.

(Rickinson et al, 2004, p.5).

This research has recently been updated by Dillon and Dickie's (2012) review of evidence that relates to the social and economic benefits of and barriers to learning in the natural environment. The authors argue that more evidence has emerged to support Rickinson et al's earlier conclusions. They report that the greatest proportion of research findings focus on the impact of outdoor learning on participants' knowledge and understanding, and show that students perform better in reading, mathematics, science and social studies, that learning outside motivates students by making subjects 'rich and relevant' (2012, p.2), and 
that students learn a broad range of skills, particularly when learning outside is integrated with the everyday school curriculum. Hands-on contact with nature stimulates an affinity towards and a greater likelihood of protecting the environment, as the concept of placebased education suggests.

Their review, however, extends beyond the parameters of Rickinson et al's to include other benefits for schools and teachers. Research shows that teachers benefit from learning outdoors, partly because learning outdoors allows them to be more creative and to devise innovative teaching strategies. Similarly, as our examples from the Natural Connections project begin to show, activities outdoors can stimulate a stronger sense of community, both within and beyond the school gates. Finally, the authors cite research that demonstrates the link between the natural environment and mental wellbeing; studies show that time outdoors can lower the effect of different issues that can make it difficult to concentrate in the classroom; community-based outdoor projects enhance the wellbeing of all participants, whatever their age. To summarise, there is significant evidence that shows benefits arising from outdoor learning include raised educational attainment, improved attitudes to other children, awareness of the environment and natural science skills, behavioural outcomes, social cohesion, health benefits and improved school staff morale (eftec, 2011).

There is recognition, however, that evidence of these benefits is fragmented (Dillon and Dickie, 2012) and that it is derived from small-scale, qualitative work; quantitative evidence that links learning in the natural environment to improvements in any of these areas is lacking (eftec, 2011). A project in Denmark, however, is starting to address these concerns. Funded by the TrygFonden, the Teachout project is investigating the impacts of udeskole, and consists of three interrelated studies that are exploring the interdependencies between children's physical activity, learning and social relations in outdoor contexts. Classes that use udeskole will be compared with non-participating classes; methods include using accelerometers to measure children's physical activity levels, analysing formal test results in Danish and mathematics, and regular surveys that are focused on participants' attitude to school and general wellbeing. It is anticipated that the findings will make a strong contribution to providing the quantitative type of knowledge that outdoor learning currently lacks (Passy et al, 2013).

Research also shows that, despite a growing awareness of the benefits of outdoor learning, there are a number of significant barriers to its practice. Dillon and Dickie (2012) suggest that these include:

- A diverse outdoor learning sector, that lacks a coherent vision of the value of learning outdoors and in which different groups and organisations work in isolation. This can make it difficult for schools to access support.

- The element of risk involved. As we saw earlier in the context of outdoor play, educators can be cautious about taking children and young people outside, stemming from a variety of factors that include interpretation of health and safety 
regulations, fear of litigation, and a sense that being outdoors wastes valuable curriculum time.

- Cost. In the current economic climate of cutback and restricted expenditure, it can be difficult for teachers to justify expense on outdoor learning without belief in and/or access to strong evidence of its benefits.

- Teachers' own views. As we have suggested, some teachers value outdoor learning, while others see learning outdoors as incompatible with their own ideas of effective pedagogy, their beliefs about the role of education and the nature of their subject.

- Time. Planning and preparing different types of lesson or activity, ensuring that the conditions outside are appropriate and devising ways to measure impact are all timeconsuming, all of which can be offputting for busy teachers.

- Confidence. The relationship between teacher and pupils changes in an outdoor context, and teachers who are used to the confines of the classroom may find it difficult to allow pupils the greater freedom that being outside brings. In addition, teachers may be unfamiliar with the natural environment themselves, and feel uncertain in these surroundings

These challenges were investigated further in research to support the development of the Natural Connections project, and this found that the amount and (un)suitable condition of local greenspace (including school grounds) is also a challenge to taking children and young people outside (Rickinson et al, 2012). Early indications from Natural Connections evaluation research suggest, however, that this challenge diminishes rapidly as teachers become more confident and adept at using the outdoors and as schools adapt and change the management of places.

While the benefits of learning outside are well-established, then, the challenges shown above demonstrate that there are numerous barriers to its adoption and that there are many teachers who are far from convinced that it is a valuable medium for teaching. Nonetheless, as the increased volume and quality of research is demonstrating, international enthusiasm for learning outside is undergoing something of a renaissance - academics and practitioners are finding new ways to theorise, approach, analyse and determine the impact of outdoor learning activities. And recently there has been some support emerging from government policy; Denmark, for example, introduced a new curriculum in 2014 that stipulates there should be more physical activity for pupils within the school day, while Singapore's new physical education curriculum has a compulsory element of outdoor learning (Passy et al, 2013). In our current context of extensive government policy borrowing, this may mean that other national curricula could be shifted to include aspects of outdoor learning in due course.

\section{Conclusion}

In this brief overview of outdoor learning, we have shown the wide variety of opportunities it can offer for children and young people's learning, along with the different barriers to its adoption in schools. Research evidence suggests that working outside can fit with a large range of curricular and non-curricular school activity, allowing schools to access the 
outdoors while accommodating different approaches to teaching, providing an enhanced educational experience and making a positive contribution to the school community. In addition, learning outside provides students with the chance to engage with the natural world which, in turn, means they are more likely to use and care for local spaces in the future. On the other hand, multiple barriers to learning outside remain, and there will always be those who remain opposed to teaching outside.

The key, however, lies with Rickinson et al's (2004) stipulation that this work should be 'properly conceived, adequately planned, well taught and effectively followed up'; as they comment, '[p]oor fieldwork is likely to lead to poor learning. Students quickly forget irrelevant information that has been inadequately presented' (2004, p.5). Research shows that preparing student teachers for outdoor learning in initial teacher training (ITT) courses in the UK has been variable in terms of time and quality (Kendall et al, 2006), and we have seen that teachers can lack confidence in their capacity to take pupils outside; recent theoretical developments show the importance of clarity of thought about the aims, purposes and potential effects of this type of education. Including outdoor learning as an intrinsic part of ITT would enable future practitioners to understand how learning outside is possible, and to decide for themselves whether to include it in their own professional practice.

To conclude, we suggest there is currently the need to make a coherent case for, and to promote the wider recognition of, the benefits that teaching outside can have across a number of areas that underpin learning, such as health and well-being, enjoyment and improved social skills, but particularly around attainment, currently one of education's chief drivers. The latter is a relatively under-researched area, and such evidence, on both national and international scales, would enable policy makers, researchers and practitioners to help 'make the case' for outdoor learning, particularly in national systems that focus strongly on pupils' levels of attainment. Support from policy makers, in turn, could help schools to develop a coherent approach to learning outside; in England, for example, it is often driven by the personal passion of an individual or individuals, which means that children often have inconsistent patterns of engagement with the natural world during their years in school.

This case could be supported by nature conservation organisations, either statutory or NGO, through enabling partnerships with schools to increase awareness and appreciation of the natural world. This could increase pro-environmental behaviours in future generations and stimulate young people to become the future environmental and ecological leaders; lifelong interest in the natural world appears to be kindled at an early age.

Finally, for those who see the benefits but who do not have the experience to develop outdoor learning in their schools, there is the need to share different models of implementation; as the Natural Connections Demonstration Project has shown, many changes to school practice can be simple to make and do not have high cost implications. As this chapter has demonstrated, teachers are starting to revisit the natural world to enhance their pupils' learning; we now need make sure this momentum continues. 


\section{References}

Aasen, W., Grindheim, L. \& Waters, J. (2009). The outdoor environment as a site for children's participation, meaning-making and democratic learning: examples from Norwegian kindergartens. Education 3-13: International Journal of Primary, Elementary and Early Years Education. 37(1): 5-13. DOI: 10.1080/03004270802291749.

Allison, P., Carr, D. \& Meldrum, G. (2012) Potential for excellence: interdisciplinary learning outdoors as a moral enterprise. Curriculum Journal, 23(1): 43-58.

Bangs, J., MacBeath, J. \& Galton, M. (2011). Reinventing Schools, Reforming Teaching: From political visions to classroom reality. Oxford and New York: Routledge.

Beames, S. \& Ross, H. (2010). Journeys outside the classroom. Journal of Adventure Education \& Outdoor Learning. 10(2): 95-109. DOI: 10.1080/14729679.2010.505708.

Becker, P. (2015). To be in the garden or not to be in the garden-that is the question here: some aspects of the educational chances that are inherent in tamed and untamed nature. Journal of Adventure Education and Outdoor Learning, 15(1): 79-92. DOI: $10.1080 / 14729679.2014 .908514$.

Bentsen, P. \& Jensen, F. (2012). The nature of udeskole: outdoor learning theory and practice in Danish schools. Journal of Adventure Education and Outdoor Learning. 12(3): 199-219. DOI: 10.1080/14729679.2012.699806.

Bentsen, P., Mygind, E. \& Randrup, T. (2009). Towards an understanding of udeskole: education outside the classroom in a Danish context. Education 3-13: International Journal of Primary, Elementary and Early Years Education. 37(1): 29-44.

Berliner, D. (2011) Rational responses to high stakes testing: the case of curriculum narrowing and the harm that follows. Cambridge Journal of Education, 41(3): 287-302. DOI: 10.1080/0305764X.2011.607151.

Blair, D. (2009). The child in the garden: An evaluative review of the benefits of school gardening. Journal of Environmental Education. 40(2): 15-38.

Brookes, A. (2003). A critique of neo-Hahnian outdoor education theory. Part one: Challenges to the concept of "character building". Journal of Adventure Education and Outdoor Learning. 3(1): 49-62. DOI: 10.1080/14729670385200241. 
Centers for Disease Control and Prevention (2013) Children's Mental Health: New Report. CDC fact sheet. http://www.cdc.gov/Features/ChildrensMentalHealth/. Accessed 16 February 2015.

Charles, C. \& Senauer, A. (2012). Health Benefits to children from contact with the outdoors and nature. Children and Nature Network Report. Available at:

http://eclkc.ohs.acf.hhs.gov/hslc/tta-system/teaching/eecd/nature-basedlearning/Research/health-benefits-from-outdoor.pdf.

Charles, C. \& Louv, R. (2009). Children's Nature Deficit: What we Know - and Don't Know. Children and Nature Network Report. https://www.childrenandnature.org/wpcontent/uploads/2015/04/CNNEvidenceoftheDeficit.pdf. Accessed 28 July 2015.

Clarke, M. (2013). Terror/enjoyment: performativity, resistance and the teacher's psyche. London Review of Education, 11(3): 229-238.

Cook, L. (1999). The 1944 Education Act and outdoor education: from policy to practice, History of Education, 28(2): 157-172.

Department for Education. (2014). Statutory framework for the early years foundation stage. UK Government policy document. https://www.gov.uk/government/uploads/system/uploads/attachment data/file/335504/EYFS framework from 1 September 2014 with clarification note.pdf. Accessed 19 February 2015.

Dillon, J. \& Dickie, I. (2012). Learning in the Natural Environment: Review of social and economic benefits and barriers. Natural England Commissioned Reports, Number 092.

Eagleton, T. (2011). Why Marx Was Right. New Haven and London: Yale University Press.

Eftec (2011). Assessing the Benefits of Learning Outside the Classroom in Natural Environments. Final Report for Natural England. Natural England Commissioned Report. http://ecosystemsknowledge.net/sites/default/files/wp-content/uploads/2013/03/Learning-inNatural-Environments-report-280211.pdf. Accessed 26 February 2015.

Elliott, H. (2014). Forest School in an inner city? Making the impossible possible. Education 3-13: International Journal of Primary, Elementary and Early Years Education. DOI: 10.1080/03004279.2013.872159.

Greenwood, D. (2013). What is Outside of Outdoor Education? Becoming Responsive to Other Places. Educational Studies: A Journal of the American Educational Studies Association. 49(5): 451-464. 
Gross, M. (2001). Unexpected Interactions: Georg Simmel and the Observation of Nature. Journal of Classical Sociology, 1(3): 395-414.

Hayhurst, J., Hunter, J., Kafka, S. \& Boyes, M. (2015). Enhancing resilience in youth through a 10-day developmental voyage. Journal of Adventure Education and Outdoor Learning. 15(1): 40-52. DOI: 10.1080/14729679.2013.843143.

Ho, S. (2014). The purposes outdoor education does, could and should serve in Singapore. Journal of Adventure Education and Outdoor Learning. 14(2): 153-171. DOI: 10.1080/14729679.2013.798587.

Järvikoski, T. (1996). The Relation of Nature and Society in Marx and Durkheim. Acta Sociologica, 39:73-86.

Jenkins, E. and Swinnerton, B. (1998). Junior School Science Education in England and Wales Since 1900: From Steps to Stages. London and Portland, Or: Woburn Press.

Kendall, S., Murfield, J., Dillon, J. \& Wilkin, A. (2006). Education Outside the Classroom: Research to Identify What Training is Offered by Initial Teacher Training Institutions. Department for Education and Skills Research Report 802. Nottingham: DfES.

Kos, M. \& Jerman, J. (2013). Provisions for outdoor play and learning in Slovene preschools. Journal of Adventure Education and Outdoor Learning. 13(3): 189-205. DOI: 10.1080/14729679.2013.769888.

Loge, A. (2009). Research and Studies: Volume Four. Children and Nature Network Report. http://www.childrenandnature.org/downloads/C\&NNRsrchVol 04 1.pdf. Accessed 17 February 2015.

Louv, R. (2008). Last child in the woods: Saving our children from nature-deficit disorder. New York: Algonquin Books of Chapel Hill.

Luchs, A. \& Fikus, M. (2013). A comparative study of active play on differently designed playgrounds. Journal of Adventure Education and Outdoor Learning. 13(3): 206-222. DOI: 10.1080/14729679.2013.778784.

Moss, S. (2012). Natural Childhood. National Trust Report. http://www.nationaltrust.org.uk/document-1355766991839/. Accessed 16 February 2015.

Natural England. (2013). Monitor of Engagement with the Natural Environment: the national survey on people and the natural environment. Annual Report form the 2012-13 survey. Natural England Commissioned Report NECR122. 
Niehues, A., Bundy, A., Broom, A., Tranter, P., Ragen, J. \& Engelen, L. (2013) Everyday uncertainties: reframing perceptions of risk in outdoor free play. Journal of Adventure Education and Outdoor Learning. 13(3): 223-237. DOI: 10.1080/14729679.2013.798588.

O'Brien, L. (2009). Learning outdoors: the Forest School approach. Education 3-13. 37(1): 45 - 60. DOI: $10.1080 / 03004270802291798$.

Passy, R. (2014). School gardens: teaching and learning outside the front door. Education 313: International Journal of Primary, Elementary and Early Years Education, 42(1): 23-38.

Passy, R. (2013). Surviving and flourishing: primary trainees talking. British Educational Research Journal, 39(6): 1060-1075.

Passy, R., Waite, S., Bentsen, P., Mygind, E., Ho, S., D'Rosario, V., Gough, N. \& Stewart, A. (2013). Policies of outdoor learning: lessons from an international comparison? Paper presented at $6^{\text {th }}$ International Outdoor Education Research Conference, University of Otago, 26-29 November.

Passy, R. \& Waite, S. (2011). School gardens and Forest Schools. In Waite, S. (Ed.). Children Learning Outside the Classroom From Birth to Eleven. London: Sage.

Passy, R., Morris, M. \& Reed, F. (2010) Impact of school gardening on learning. Final report submitted to the Royal Horticultural Society. Royal Horticultural Society commissioned research. http://apps.rhs.org.uk/schoolgardening/default.aspa. (Accessed 25 February 2015).

Pike, E. \& Beames, S. (2013). Outdoor Education and Social Theory. Abingdon and New York: Routledge.

Rea, T. (2011). Residential centres: desirable difference? In Waite, S. (Ed.) (2011). Children Learning Outside the Classroom From Birth to Eleven. London: Sage.

Rickinson, M., Hunt, A., Rogers, J. \& Dillon, J. (2012). School Leader and Teacher Insights into Learning Outside the Classroom in Natural Environments. Natural England Commissioned Reports, Number 097

Rickinson, M., Dillon, J., Teamey, K., Morris, M., Choi, M. Y., Sanders, D., \& Benefield, P. (2004). A review of research on outdoor learning. London: Field Studies Council.

Robinson, K. (2010). Changing Education Paradigms. RSA YouTube video. https://www.youtube.com/watch?v=zDZFcDGpL4U. Accessed 13 February 2015. 
Roe, D. (n/d). The Pre-Raphaelites. Resource document. British Library. http://www.bl.uk/romantics-and-victorians/articles/the-pre-raphaelites\#footnote1. Accessed 11 February 2015.

Sandseter, E., Little, H \& Wyver, S. (2012). Do theory and pedagogy have an impact on provisions for outdoor learning? A comparison of approaches in Australia and Norway. Journal of Adventure Education and Outdoor Learning. 12(3): 167-182. DOI: 10.1080/14729679.2012.699800.

Sellar, S. \& Lingard, B. (2013). PISA and the expanding role of the OECD. In Meyer, H-D. \& Benavot, A. (Eds.), PISA, Power and Policy: the emergence of global educational governance. Oxford: Symposium Books.

Steiner-Khamsi, G. (2012). Building Comparative Policy Studies. In Steiner-Khamsi, G. \& Waldow, F. (Eds.), World Yearbook of Education 2012: Policy Borrowing and Lending in Education. London and New York: Routledge.

Stewart, A. (2008). Whose place, whose history? Outdoor environmental education pedagogy as 'reading' the landscape. Journal of Adventure Education \& Outdoor Learning. 8(2): 79-98. DOI: 10.1080/14729670801906125.

Taylor, C., Power, S \& Rees, G. (2010) Out-of-school learning: the uneven distribution of school provision and local authority support. British Educational Research Journal, 36(6): 1017-1036.

Tranter, P. \& Malone, K. (2004). Geographies of environmental learning: an exploration of children's use of school grounds. Children's Geographies.2(1): 131-155.

Waite, S. (2013). Knowing your place in the world': how place and culture support and obstruct educational aims. Cambridge Journal of Education. 43(4): 413-433. DOI: 10.1080/0305764X.2013.792787.

Waite, S. (Ed.) (2011). Children Learning Outside the Classroom From Birth to Eleven. London: Sage.

Waite, S. (2010). Losing our way? The downward path for outdoor learning for children aged 2-11 years. Journal of Adventure Education and Outdoor Learning, 10(2): 111-126.

Waite, S., Rogers, S. \& Evans, J. (2013). Freedom, flow and fairness: exploring how children develop socially at school through outdoor play. Journal of Adventure Education and Outdoor Learning. 13(3): 255-276. DOI: 10.1080/14729679.2013.798590. 
World Health Organisation (2015). Obesity and overweight. World Health Organisation Fact Sheet No. 11. http://www.who.int/mediacentre/factsheets/fs311/en/. Accessed $16^{\text {th }}$ February 2015.

World Health Organisation (2014). Mental Health: strengthening our response. World Health Organisation Fact Sheet no. 220. http://www.who.int/mediacentre/factsheets/fs220/en/ (accessed 16 February 2015).

YoungMinds (2015) Mental Health Statistics. YoungMinds information sheet.

http://www.youngminds.org.uk/training services/policy/mental health statistics. Accessed 16 February 2015.

Zink, R. \& Burrows, L. (2008). 'Is what you see what you get?' The production of knowledge in-between the indoors and the outdoors in outdoor education. Physical Education and Sport Pedagogy. 13(3): 251-265. 